\section{Presentation rates and verbal discrimination} learning ${ }^{1}$

SHARRON S. WIKE and EDWARD L. WIKE, University of Kansas, Lawrence, Kans. 66044

The effects of 1-, 2-, 4-, and 8-sec anticipation times and 1-, 2-, 4, and 8-sec study times on verbal discrimination learning were investigated using 192 college students. In Experiment 1 (96 Ss), the items were more meaningful and there were fewer pairs of items than in Experiment 2. In Experiment 1, anticipation time alone was significant, with better performance resulting from a longer anticipation time. In Experiment 2 (96 Ss), both study time and anticipation time were significant; with longer times, better performance was found. The results were discussed in terms of frequency theory.

According to the Ekstrand, Wallace, \& Underwood (1966) theory of verbal discrimination learning, the cue for discrimination is the subjective difference in the frequency of occurrence between the correct and incorrect members of each verbal discrimination pair. Concerning presentation rates and verbal discrimination learning, they offered the following predictions: "The theory makes a rather unusual prediction with regards to the effects of anticipation time. A large increase in anticipation time, with study time held constant, should have no effect on VD [verbal discrimination] performance, or perhaps even an inhibitory effect .... On the other hand, if study time after reinforcement is increased, the theory predicts better performance... [Ekstrand et al, 1966, p. 576]."

There have been several studies on rate of presentation and verbal discrimination. Four studies combined an increase in anticipation time with an increase in study time (McClelland, 1942; Underwood \& Viterna, 1951; Underwood \& Archer, 1955; Sippola, 1967). In these studies longer time was associated with better performance, but whether the increase in performance was due to a longer anticipation time, study time, or both cannot be determined since both times were varied simultaneously.

In three studies, anticipation time alone was varied (Underwood, Jesse, \& Ekstrand, 1964; Crouse, 1967; Wike, 1970). Underwood et al and Crouse varied anticipation time in a second task transfer situation. Thus, rate in the second task was longer interval. increases.

\section{EXPERIMENT 1}

Method confounded with changes in rate from the first to the second task. Both studies, contrary to the prediction from frequency theory, found better learning with the longer anticipation time. Wike (1970), who held study time constant, found no significant effect of anticipation time although there were fewer errors with a

The present two studies were parametric studies on rate of presentation and verbal discrimination learning. Both Experiment 1 and Experiment 2 were 4 by 4 factorial designs in which 1-, 2-, 4-, and 8-sec anticipation times were crossed with 1-, 2-, 4-, and 8-sec study times. According to frequency theory, performance should improve as study time increases but remain the same or worsen as anticipation time

There were 100 Ss. Four Ss were lost in the experiment, two because of $\mathrm{E}$ error, one due to apparatus failure, and one because he misunderstood the instructions. Thus, $96 \mathrm{Ss}, 32$ males and 64 females, completed the experiment. The Ss were undergraduate volunteers from the introductory psychology course at the University of Kansas. The Ss were assigned randomly and equally to the 16 conditions described below.

The apparatus consisted of a Sawyer Rotomatic slide projector, Model 700, which was programmed by three timers. The timers were activated by a power supply. The presentation rates were 1-, 2-, 4-, and 8-sec anticipation times combined with 1-, 2-, 4-, and 8-sec study times.

The material consisted of 34 high-meaningful CVCs, with a rated meaningfulness of 4.08 to 4.78 (Noble, 1961). Two items were used in the instructions; the remaining 32 words were randomly combined into 16 pairs. The 16 pairs were administered in three randomly determined interpair orders. In the first and third presentation order the intrapair order (right-left) differed from the second

Table 1

Mean Total Errors During Learning for Experiment 1 and Experiment 2

\begin{tabular}{lrrrr}
\hline Presentation Rate & $1 \mathrm{Sec}$ & $2 \mathrm{Sec}$ & $4 \mathrm{Sec}$ & $8 \mathrm{Sec}$ \\
\hline Experiment 1 & & & & \\
$\quad$ Anticipation Time & 10.71 & 8.92 & 9.79 & 3.67 \\
Study Time & 7.83 & 10.54 & 8.67 & 6.04 \\
Experiment :2 & & & & \\
$\quad$ Anticipation Time & 45.08 & 37.96 & 32.67 & 32.96 \\
Study Time & 45.08 & 39.17 & 36.46 & 27.96 \\
\hline
\end{tabular}

order. In each interpair order an equal number of correct items were on the right and left.

There were 100 slides in the circular projector drum. The three interpair orders of the 16 pairs and their respective feedback items accounted for 96 slides. There were two blank slides before the first interpair order of the list and two blank slides between the first and second interpair order.

The instructions were standard verbal discrimination instructions in which $S$ was instructed to guess on the first trial. The $S$ was told that the task would continue until he got all items correct two times in a row or for $\mathbf{1 0}$ trials, whichever came first. Results

The measure of learning was the total number of errors from Trial 2 to the criterion trial or to Trial 10 . If $S$ met the criterion of two successive trials without an error, it was assumed that his performance would continue to be perfect. The total numbers of errors for all Ss were submitted to a two-factor analysis of variance. The only significant factor was anticipation time $(F=5.32, \mathrm{df}=3 / 80, \mathrm{p}<.01)$. The mean errors for the four anticipation groups and the four study time groups are presented in Table 1. Pairwise comparisons of the anticipation means by Tukey's b method (Winer, 1962) revealed that the 8-sec group made significantly $(p<.01)$ fewer errors than the $1-\mathrm{sec}$ and 4 -sec groups, but there were no other significant differences among the means.

The task was an easy one for most of the Ss. For example, over one-third of the Ss made five or fewer total errors. Perhaps the simplicity of the task was why there was no effect of study time. Accordingly, Experiment 2 was conducted in which an attempt was made to increase the difficulty of the task by using 24 pairs of low-meaningful items.

\section{EXPERIMENT 2 Method}

The Ss came from the same population as Experiment 1. There were $101 \mathrm{Ss}$, but three Ss were lost as a result of apparatus failure, one misunderstood the instructions, and one was lost due to $\mathrm{E}$ error. Thus, there were $96 \mathrm{Ss}, 49$ males and 47 females, in the experiment proper and 
the Ss were assigned randomly and equally to the 16 experimental conditions.

Experiment 2 closely resembled Experiment 1 in apparatus, instructions, and procedure. However, the material used for Experiment 2 differed from that of Experiment 1. The material consisted of 50 low-meaningful CVCs. The items were arranged to minimize intrapair similarity. One pair of items was used in the instructions; the remaining 24 pairs were arranged randomly in two interpair orders and two intrapair orders. An equal number of correct items appeared on the right and the left in each interpair order. Two blank slides appeared before the first interpair order and two before the second interpair order. The Ss were instructed to pronounce the chosen syllable. Again, the presentation rates were 1-, 2-, 4-, and 8-sec anticipation times combined with 1-, 2-, 4-, and 8-sec study times.

\section{Results}

The learning measure was identical to that used in Experiment 1. The total errors for the Ss were submitted to a two-factor analysis of variance. Both anticipation time $(\mathrm{F}=3.30$, df $=3 / 80, \mathrm{p}<.025)$ and study time were significant $(F=4.95, \mathrm{df}=3 / 80$, $p<.005$ ). The mean errors for the four anticipation and the four study time groups are displayed in Table 1. Pairwise comparisons of means by Tukey's b test revealed that: (1) the 4- and the 8 -sec anticipation groups made significantly $(\mathrm{p}<.05)$ fewer errors than the 1 -sec group, and (2) the 8-sec study time group erred significantly $(\mathrm{p}<.01)$ less than the $1-\mathrm{sec}$ group. None of the remaining comparisons was significant.

\section{DISCUSSION}

In Experiment 1, an increase in study time did not lead to significantly better performance, while in Experiment 2, an increase in study time was associated with better performance. Experiment 1 and Experiment 2 differed primarily in two ways: (1) there were more pairs of items in Experiment 2, and (2) the items in Experiment 2 were of lower meaningfulness. If meaningfulness is the more crucial factor of these two, then it could be said that when the words are very easy (e.g., such words as dog, men, car, war), a short study time is as effective as 8 -sec study time. When the items are more difficult (e.g., such CVCs as suv, xas, hix, jec), an 8-sec study time is more helpful.

It may be that it is the increase in number of pairs of items or both factors together that explains the discrepancy in the study time results between Experiment 1 and Experiment 2. Further research, e.g., variation in meaningfulness with list length held constant, is needed in order to clarify these results.

In both experiments, an increase in anticipation time was associated with better performance. This result agrees generally with previous studies and is directly opposed to the prediction by Ekstrand et al. Seemingly, however, Ekstrand et al assumed that when a pair of items or the correct item was being presented, the $S$ concentrated his efforts only on that pair of items or item, that is, that he was not rehearsing other items. After the learning task, the Ss in Experiment 2 were asked if they had, many times, practiced a correct item from one pair while another pair or its correct item was being shown. Fifty seven of the 96 Ss reported such displaced rehearsals. Perhaps the longer anticipation time is more effective than a shorter time because it allows time for more such rehearsals. If this supposition is true, then the results are not in complete disagreement with frequency theory. Rather, frequency theory needs to encompass the frequency units that are added by displaced rehearsals.

It seems doubtful if the effectiveness of a longer anticipation rate can be explained solely on the basis of displaced rehearsals. In Experiment 1, anticipation time was significant but study time was not. Surely, displaced rehearsals are not more effective than rehearsals in context. Perhaps another factor is operating with respect to anticipation time. Maybe $S$ can discriminate a difference in frequency units better when he has a longer anticipation time. Thus, two possible reasons are suggested as to why, contrary to frequency theory, a longer anticipation time leads to better performance: (1) With a longer time, there is opportunity for more displaced rehearsals; and (2) with a longer time, frequency discrimination may be more effective. Neither of these factors was included in the original version of frequency theory.

\section{REFERENCES}

CROUSE, J. H. Verbal discrimination transfer in two paradigms as a function of conceptual similarity and anticipation interval. Journal of Verbal Learning \& Verbal Behavior, 1967, 6, 277-281.

EKSTRAND, B. R., WALLACE, W. P., \& UNDERWOOD, B. J. A frequency theory of verbal-discrimination learning. Psychological Review, 1966, 73, 566-578.

McCLELLAND, D. C. Studies in serial verbal discrimination learning: I. Reminiscence with two speeds of pair presentation. Journal of Experimental Psychology, 1942, 31, 44-56.

NOBLE, C. E. Measurements of association value (a), rated associations (a'), and scaled meaningfulness $\left(m^{\prime}\right)$ for $2100 \mathrm{CVC}$ combinations of the English alphabet. Psychological Reports, 1961, 8, 487-521.

SIPPOLA, B. C. Verbal discrimination learning and the length-difficulty law. Unpublished doctoral dissertation, The University of Kansas, 1967.

UNDERWOOD, B. J., \& ARCHER, E. J. Studies of distributed practice: XIV. Intra-list similarity and presentation rate in verbal-discrimination learning of consonant syllables. Journal of Experimental Psychology, 1955, 50, 120-124.

UNDERWOOD, B. J., JESSE, F., \& EKSTRAND, $B$. R. Knowledge of rights and wrongs in verbal discrimination learning. Journal of Verbal Learning \& Verbal Behavior, 1964, 3, 183-186.

UNDERWOOD, B. J., \& VITERNA, R. O. Studies of distributed practice: IV. The effect of similarity and rate of presentation in verbal discrimination learning. Journal of Experimental Psychology, 1951, 42, 296-299.

WIKE, S. S. The effects of feedback, guessing, and anticipation rate upon verbal discrimination learning. Psychological Record, in press.

WINER, B. J. Statistical principles in experimental design. New York: McGraw-Hill, 1962.

\section{NOTE}

1. These studies were supported by a grant, HD 00870 , from the National Institute of Child Health and Human Development and a Biomedical Sciences Support grant, FR-07037. 